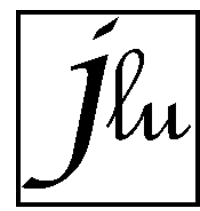

https://jurnal.univpgri-

palembang.ac.id/index.php/luminous

\title{
IDENTIFIKASI PENGETAHUAN STANDARISASI ALAT PRAKTIKUM DAN KETERAMPILAN ASISTEN LABORATORIUM FISIKA DASAR DI UIN WALISONGO SEMARANG
}

\author{
Fenaldi Afik Saputro ${ }^{1}$ dan Susilawati ${ }^{2}$ \\ ${ }^{1}$ Pendidikan Fisika, Fakultas Sains dan Teknologi, Universitas Islam Negeri Walisongo Semarang \\ JI. Prof. Hamka (Kampus II) Ngaliyan, Semarang 50185 \\ fenaldia@gmail.com \\ ${ }^{2}$ Pendidikan Fisika, Fakultas Sains dan Teknologi, Universitas Islam Negeri Walisongo Semarang \\ JI. Prof. Hamka (Kampus II) Ngaliyan, Semarang 50185 \\ susilawati@walisongo.ac.id
}

Received: 28 April 2020. Accepted: 25 Juni 2020. Published: Juli 2020

Abstrak

\begin{abstract}
Kualitas pelaksanaan laboratorium akan sangat ditentukan oleh asisten laboratorium yang melakukan pendampingan praktikum. Asisten laboratorium yang melaksanakan tugasnya dengan baik sesuai dengan standar kinerja laboratorium akan meningkatkan kualitas dari suatu laboratoium. Penelitian ini bertujuan untuk mengidentifikasi pengetahuan asisten laboratorium tentang standarisasi alat praktikum fisika dasar I dan keterampilan kinerja awal pada laboratorium fisika UIN Walisongo Semarang untuk mengetahui kesiapan dari asisten laboratorium dalam melaksanakan pendampingan praktikum. Metode penelitian yang digunakan adalah deskriptif kuantitatif dengan teknik pengambilan data melalui kuisioner dan wawancara. Berdasarkan hasil penelitian dinyatakan bahwa pengetahuan asisten laboratorium terkait standar spesifikasi alat diperoleh nilai persentase rata-rata $72,7 \%$ dan pengetahuan asisten laboratorium terkait standar penggunaan alat diperoleh nilai persentase rata-rata $91 \%$. Pengetahuan asisten laboratorium terkait standarisasi alat praktikum dipengaruhi oleh pelatihan asisten laboratorium yang merupakan bekal yang mendasar sebelum terjun sebagai pendamping praktikum dan ditambah dengan latihan mandiri dan kelompok asisten fisika dasar dengan arahan dosen pengampu praktikum.
\end{abstract}

Kata Kunci: standarisasi alat praktikum, keterampilan kinerja laboratorium, fisika dasar 


\section{PENDAHULUAN}

Praktikum Fisika Dasar sangat membutuhkan sarana dan prasarana yang mendukung untuk melaksanakan pembelajaran sebagaimana mestinya sesuai dengan kurikulum masing-masing program studi (Nikmah, Hartono, \& Sujarwata, 2017) Jurusan fisika sebagai salah satu dari jurusan ilmu pengetahuan alam yang secara konseptual dikembangkan melalui eksperimen serta pengamatan fenomena alam. Hal tersebut mengindikasikan bahwa fisika tidak hanya berfokus pada teori seperti cabang ilmu secara umum, akan tetapi dibutuhkan suatu pembuktian pada teori yang akan digunakan. Pembuktian tersebut biasanya dilakukan di tempat yang memiliki peralatan khusus sehingga memungkinkan akan muncul kerangka pemikiran ilmiah untuk memperoleh jawaban dari hipotesis suatu permasalah fisika yang disebut sebagai laboratorium fisika (Khasanah, 2013).

Laboratorium fisika dalam pembelajaran di perguruan tinggi digunakan untuk mencapai tujuan kognitif seperti belajar konsep ilmiah, meningkatkan pemahaman terhadap metode ilmiah serta pengembangan science procces skill (Mastika, Adnyana, \& Setiawan, 2014). Pembelajaran dalam laboratorium fisika akan berjalan sebagaimana mestinya apabila suatu laboratorium sudah memenuhi kriteria tertentu agar mampu dimanfaatkan secara efektif dan efisien.

Kementerian Pendidikan menyatakan standar minimal untuk sarana prasarana meliputi bangunan, perabotan, media pendidikan, alat dan bahan praktikum, peralatan $\mathrm{P} 3 \mathrm{~K}$, serta peralatan pendukung lainnya (Menteri Pendidikan Nasional Republik Indonesia, 2007). Laboratorium fisika juga membutuhkan sumber daya manusia yang berkualitas untuk melakukan pengelolaan laboratorium yang biasa dikenal dengan tenaga laboratorium. Adapun enaga laboratorium fisika meliputi kepala laboratorium, teknisi, dan laboran. Kepala laboratorium memiliki tugas untuk merencanakan serta melakukan pengelolaan laboratorium dan membagi tugas antara teknisi dan laboran. (Menteri Pendidikan Republik Indonesia, 2008) Teknisi bertugas untuk melakukan perawatan dan perbaikan sarana prasarana laboratorium serta melakukan prosedur penyimpanan alat dan bahan sesuai dengan jenisnya (Sunardiyo, 2014). Laboran memiliki tugas untuk menginventarisasi alat dan bahan, merawat laboratorium, serta melayani kegiatan praktikum atau percobaan di laboratorium. Tugas laboran biasanya dibantu oleh guru pengampu praktikum yang bertugas untuk merencanakan praktikum yang akan diterapkan dan asisten laboratorium untuk membimbing praktikan dalam pengambilan data percobaan (Suwardi, 2016)

Tenaga laboratorium yang berperan dalam pengoptimalan laboratorium harus melaksanakan tugas yang diamanahkan dengan baik dan sistematis. Pelaksanaan tugas tenaga laboratorium dibuktikan oleh laporan pertanggungjawaban secara periodik. Sumber daya manusia laboratorium yang meliputi tenaga laboratorium, guru pengampu praktikum, dan asisten laboratorium hendaknya terlebih dahulu mengetahui standar yang harus dimiliki oleh laboratorium fisika sebelum dioperasionalkan (Sunardiyo, 2014).

Berdasarkan permasalahan standar laboratorium yang harus diketahui oleh sumber daya manusia yang bertugas pada suatu laboratorium, maka dilakukan sebuah penelitian untuk mengidentifikasi pengetahuan asisten laboratorium tentang standarisasi alat praktikum fisika dasar pada laboratorium fisika I UIN Walisongo Semarang. Penelitian ini hanya dilakukan pada asisten laboratorium karena tugas yang dilakukan harus bertatap muka secara langsung dengan praktikan untuk pendampingan 
pengambilan data praktikum, sehingga dibutuhkan pengetahuan yang mumpuni terkait standarisasi alat praktikum yang akan digunakan.

\section{METODE}

Metode yang digunakan dalam penelitian ini adalah deskriptif kuantitatif yang merupakan sebuah cara untuk mengetahui kejadian pada suatu sampel dengan data berupa angka yang diperoleh melalui suatu langkah-langkah penelitian secara sistematis (Sugiyono, 2009). Penggunaan metode tersebut bertujuan agar pemetaan pengetahuan asisten laboratorium praktikum fisika dasar I menjadi lebih valid sehingga mudah untuk dianalisis. Penelitian ini di laksanakan pada 2 Maret - 24 Mei 2020. Subyek penelitian ini adalah asisten laboratorium praktikum fisika dasar I. Pengambilan data dilakukan dengan kuisioner dan wawancara untuk mengetahui pengetahuan asisten laboratorium tentang standarisasi alat praktikum dan penggunaan alat praktikum fisika dasar I. Kuisioner menggunakan skala Likert dengan gradasi 3 pilihan dan wawancara dilakukan secara terbuka. Data yang sudah terkumpul disusun dalam bentuk skor berskala interval.

Tabel 1. Tabel Data Interval Klsifikasi

\begin{aligned} & Persentase Klasifikasi \\ & \hline $85 \%<X \leq 100 \%$ Sangat Baik \\ & $65 \%<X \leq 85 \%$ Baik \\ & $45 \%<X \leq 65 \%$ Cukup \\ & $25 \%<X \leq 45 \%$ Kurang \\ & $0 \%<X \leq 25 \%$ Sangat Kurang \\ & \hline\end{aligned}

HASIL DAN PEMBAHASAN
Penelitian ini dilakukan secara daring (online) melibatkan 11 asisten laboratorium fisika dasar I yang terdiri dari 6 mahasiswa angkatan 2017 dan 5 mahasiswa angkatan 2018. Hasil penelitian pengetahuan asisten laboratorium tentang standar spesifikasi alat praktikum fisika dasar I disajikan pada Gambar 1.

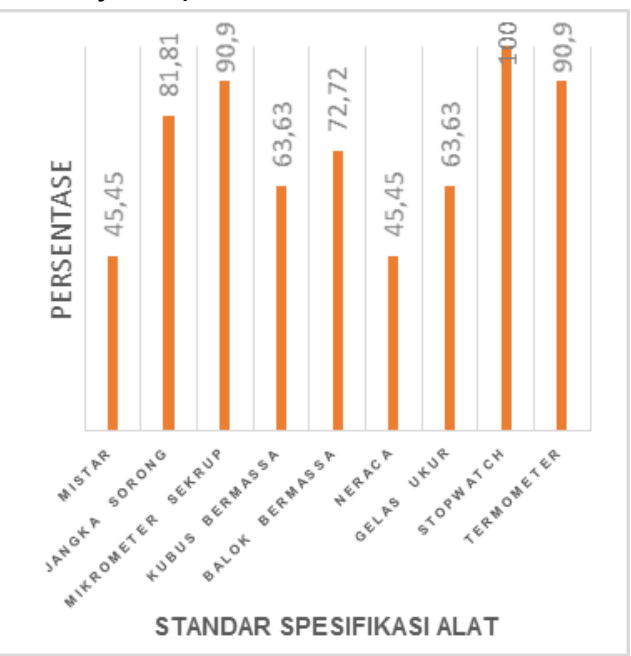

Gambar 1. Pengetahuan Standar Spesifikasi Alat

Hasil penelitian menunjukkan bahwa pengetahuan terkait standar spesifikasi alat oleh asisten laboratorium praktikum fisika dasar I memiliki persentase tertinggi sebesar $100 \%$ pada alat fisika berupa stopwatch. Persentase tersebut menunjukkan bahwa asisten laboratorium telah mengetahui secara detail karakteristik stopwatch yang harus disediakan pada suatu laboratorium fisika. Pengetahuan terkait standar spesifikasi alat oleh asisten laboratorium praktikum fisika dasar I yang memiliki persentase terendah adalah neraca dan mistar sebesar $45,45 \%$. Persentase alat fisika berupa neraca dan mistar memiliki persentase yang sangat rendah dikarenakan oleh pengetahuan asisten laboratorium yang hanya mengetahui spesifikasi alat melalui pengalaman pribadi tanpa dasar teori yang jelas. Namun, setelah dilakukan rerata pada semua alat praktikum fisika dasar I yang digunakan untuk mengetahui pengetahuan asisten laboratorium tentang standar spesifikasi alat menunjukkan dalam kategori baik dengan persentase $72,7 \%$. 
Standar spesifikasi alat yang dimaksud dalam penelitian ini berdasarkan Permendiknas No. 24 Tahun 2007. Acuan minimum bagi suatu laboratorium untuk melakukan pengadaan prasarana laboratorium meliputi yaitu perabot, alat peraga, perkakas, serta alat penunjang lainnya. Acuan minimum ini harus mampu dipenuhi oleh setiap instansi ketika akan mendirikan sebuah laboratorium untuk meminimalisir kecelakaan kerja laboratorium. Standar alat praktikum laboratorium fisika juga sudah diatur dengan jelas jumlah minimal serta spesifikasi alat praktikum. Hal ini bertujuan agar asisten laboratorium mengetahui hal-hal penting dalam pemilihan alat yang digunakan dalam praktikum. Hasil tersebut juga menunjukkan hal yang sesuai dengan hasil wawancara, dimana setelah dipilih sebagai asisten praktikum pada awal semester, ternyata responden menyatakan bahwa tidak ada pelatihan atau pengarahan khusus terkait spesifikasi alat praktikum fisika dasar I. Responden mengetahui berbagai spesifikasi alat tersebut berdasarkan pengalaman lapangan ketika melakukan pendampingan praktikum. Pemahaman tersebut muncul ketika terjadi pengulangan asistensi atau pendampingan praktikum pada kelas yang berbeda, sehingga lama kelamaan responden akan memahami standar spesifikasi alat tanpa melalui pelatihan formal yang dilakukan oleh laboratorium fisika. Tidak adanya pelatihan formal bagi asisten laboratorium praktikum fisika dasar I membuat hasil penelitian tidak sesuai harapan. Hal tersebut dikarenakan oleh alat praktikum fisika yang digunakan dalam penelitian ini merupakan alat-alat dasar yang harus dikuasai oleh asisten laboratorium fisika dasar I yang bertugas membantu dosen dalam memberikan informasi terkait alat-alat yang akan digunakan dalam praktikum.

Pengetahuan terkait standar spesifikasi alat praktikum fisika dasar I menjadi modal utama bagi seorang asisten laboratorium untuk melakukan pendampingan praktikum. Pengetahuan tersebut diharapkan mampu membawa laboratorium fisika menjadi tempat yang efektif untuk pembelajaran dengan memberikan bimbingan kepada praktikan melalui asisten laboratorium untuk menumbuhkan sikap ilmiah dalam proses pembelajaran praktikum (Berliani, 2019). Praktikum yang menjadi alternatif pembentukan tiga aspek kompetensi praktikan yang meliputi aspek kognitif, psikomotorik dan afektif dapat terbentuk secara lebih optimal dengan bantuan asisten laboratorium yang telah menguasai pengetahuan standar spesifikasi alat praktikum yang digunakan.

Proses pembelajaran dalam praktikum tidak terlepas dengan peran asisten laboratorium dalam melakukan pendampingan. Pendampingan yang dilakukan oleh asisten laboratorium juga harus memiliki kualitas yang setara dengan kelengkapan sarana dan prasarana pendukung. Sehingga perlu adanya pengetahuan terkait pengunaan alat praktikum sesuai dengan kondisi sarana dan prasarana yang akan digunakan pada praktikum. Oleh karena itu, perlu adanya suatu penelitian untuk mengetahui kemampuan dari asisten laboratorium dalam menggunakan alat-alat praktikum yang akan digunakan untuk paraktikum. Hasil penelitian tentang penggunaan alat praktikum fisika dasar I disajikan pada Gambar 2.

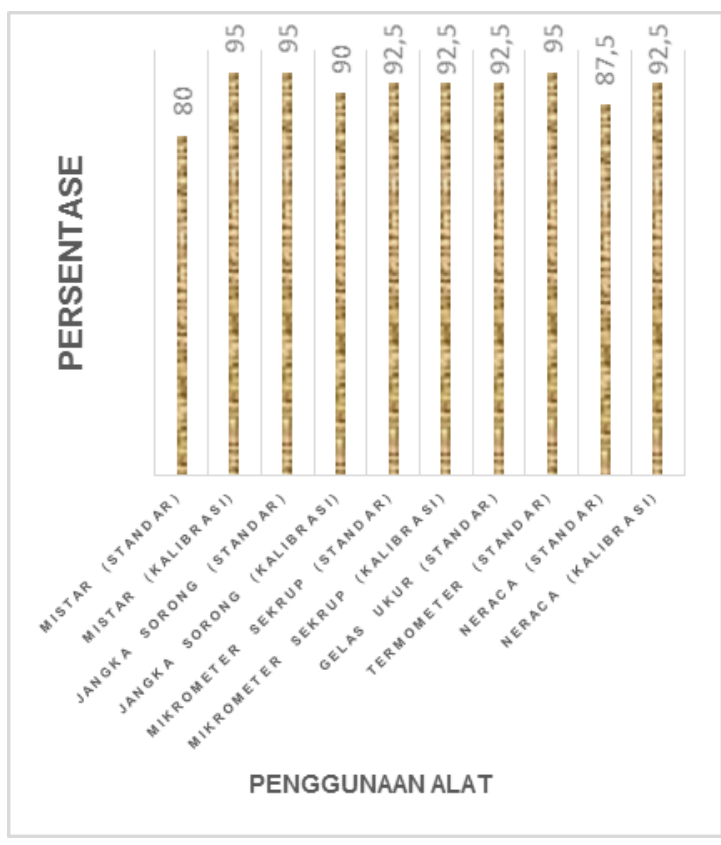




\section{Gambar 2. Pengetahuan Penggunaan Alat}

Hasil penelitian menunjukkan bahwa pengetahuan terkait penggunaan alat ukur fisika memiliki persentase tertinggi pada mistar yang membutuhkan kalibrasi, jangka sorong yang masih dalam kondisi standar, dan termometer yang masih standar dengan persentase 95\%. Persentase terendah terkait pengetahuan penggunaan alat praktikum fisika dasar I adalah penggunaan mistar yang masih standar dengan persentase $\quad 80 \%$. Pengetahuan terkait penggunaan mistar standar memiliki nilai persentase yang cukup kecil dikarenakan penggunaan mistar oleh asisten laboratorium cenderung mengabaikan titik akhir hasil pengukuran sehingga hasil yang didapatkan tidak valid. Kebanyakan asisten laboratorium menyatakan lebih teliti dalam mengamati penggunaan mistar yang perlu dikalibrasi karena titik awal yang digunakan bukan nol sehingga perlu perhatian yang lebih dalam melakukan pengukuran. Namun setelah dilakukan rata-rata pada pengetahuan asisten laboratorium terkait penggunaan alat praktikum menunjukkan kategori sangat baik yaitu dengan persentase rata-rata $91 \%$. Pengetahuan penggunaan alat praktikum pada penelitian ini diterapkan pada alat yang masih dalam kondisi baik dan beberapa alat yang sudah sedikit rusak (error) sehingga membutuhkan kalibrasi terlebih dahulu. Hal tersebut dilakukan sebagai penelitian karena kondisi real dari laboratorium fisika UIN Walisongo Semarang yang mempunyai alat dalam kondisi baik dan beberapa dalam kondisi sedikit rusak. Kondisi yang laboratorium fisika yang memiliki kualitas alat yang sangat beragam harus mampu dioptimalkan penggunaanya. Pengetahuan penggunaan alat praktikum dalam berbagai kondisi baik itu standar ataupun sedikit rusak (error) dirasa sangat penting untuk dimiliki seorang asisten laboratorium agar mudah beradaptasi pada kondisi yang berubah sewaktu-waktu.

Hasil tersebut berbeda dengan penelitian yang telah dilakukan oleh (Suwardi, 2016) menunjukkan bahwa pengetahuan penguasaan alat praktikum pada kategori baik persentase $70 \%$. Hal tersebut ternyata dipengaruhi oleh tidak ada pelatihan sebelum melakukan asistensi/ pendampingan praktikum. Namun, hasil wawancara pada penelitian menunjukkan hubungan dengan hasil kuisioner dimana responden telah mendapatkan pelatihan penggunaan alat terlebih dahulu oleh laboratorium fisika dengan bimbingan laboran diawal semester. Selain itu, pada pertemuan pertama praktikum fisika dasar I dilakukan demonstrasi alat oleh asisten yang diawasi oleh laboran, sehingga ketika terjadi miskomunikasi penggunaan alat praktikum maka dapat diperbaiki dan direvisi secara langsung.

Pengetahuan asisten laboratorium terkait alat praktikum yang meliputi spesifikasi alat dan penggunaan dapat meminimalisir miskonsepsi dalam menjelaskan langkah kerja praktikum kepada praktikan. Selain itu, (Sakti, 2011) memaparkan bahwa terdapat pengetahuan alat praktikum dapat berkontribusi sebesar 55,8 \% dengan kemampuan psikomotorik asisten laboratorium. Pengetahuan tersebut juga berguna untuk memberikan kontribusi dalam pengoptimalan proses pembelajaran laboratorium yang dapat digunakan untuk mengetahui ketersediaanya alat baik secara kualitatif dan kuantitatif serta relevan dengan kurikulum pembelajaran fisika di perguruan tinggi.

Pentingnya pengetahuan standarisasi alat praktikum memungkinkan menjadi dasar untuk melatih keterampilan abad 21 (Putri, Risdianto \& Sutarno, 2017). Asisten praktikum fisika dasar memiliki keterampilan laboratorium untuk mendampingi praktikan merancang praktikum, melaksanakan praktikum dan melaporkan kegiatan praktikum (Pujani, 2014). Pengalaman belajar calon guru fisika dalam merancang proyek sederhana praktikum dibutuhkan kemampuan menemukan ide dan melakukan pengujian alat praktikum (Susilawati, et al., 2020). Hal ini membutuhkan penguasaan standarisasi alat praktikum. Keterampilan lainnya diperlukan untuk 
menunjukkan penguasaan praktikum fisika dasar adalah penguasaan teorinya melalui keterampilan argumentasi (Susilawati, 2020). Keterampilan ini menstimulasi penalaran ilmiah, rasional, konsep ilmiah dan data sebagai bukti.

\section{KESIMPULAN DAN SARAN}

Pengetahuan asisten laboratorium mengenai standarisasi alat praktikum fisika dasar I laboratorium fisika meliputi pengetahuan standar spesifikasi alat praktikum yang memiliki kriteria baik dengan persentase $72,7 \%$ dan pengetahuan penggunaan alat praktikum yang memiliki kriteria sangat baik dengan persentase rata-rata $91 \%$. Hasil identifikasi pengetahuan asisten laboratorium fisika tersebut menunjukkan bahwa asisten laboratorium telah siap untuk melakukan pendampingan praktikan pada kegiatan praktikum fisika dasar I UIN Walisongo Semarang. Faktor yang mempengaruhi kurang maksimalnya pengetahuan standar spesifikasi alat praktikum fisika dasar I adalah tidak adanya pelatihan khusus tentang standar spesifikasi alat praktikum.

Saran yang diberikan berdasarkan penelitian ini adalah perlunya sinergisitas antara berbagai pihak di laboratorium terutama asisten laboratorium dengan regulasi yang memudahkan dalam pengoptimalan kinerja dari asisten. Hal tersebut dapat diwujudkan melalui pelatihan asisten laboratorium secara bertahap dan terstruktur untuk meningkatkan pengetahuan spesifikasi alat dan penggunaan alat laboratorium fisika. Selain itu, perlu adanya pengembangan penelitian terkait standarisasi laboratorium fisika UIN Walisongo untuk melakukan masukan kepada program studi dan laboratorium guna melakukan manejemen laboratorium secara baik dan sistematis.

\section{UCAPAN TERIMA KASIH}

Terima kasih disampaikan kepada Laboratorium Fisika UIN Walisongo Semarang yang telah memberikan ijin pelaksanaan penelitian ini. Terima kasih juga kepada seluruh asisten Laboratorium Fisika UIN Walisongo Semarang sebagai responden pada penelitian ini. Terima kasih kepada program studi pendidikan fisika UIN Walisongo Semarang untuk dukungannya dalam pelaksanaan penelitian ini

\section{DAFTAR PUSTAKA}

Berliani, S. (2019). Analisis Standardisasi Laboratorium Dalam Proses Pembelajaran Fisika (Studi Kasus di MAN 4 Aceh Besar). UIN Ar-Raniry Banda Aceh.

Khasanah, N. (2013). Studi Kelengkapan dan Pemanfaatan Alat Praktikum Fisika Kelas $X$ SMA Sebagai Implementasi Kurikulum Tingkat Satuan Pendidikan di Kota Yogyakarta. UIN Sunan Kalijaga Yogyakarta.

Mastika, I. N., Adnyana, I. B. P., \& Setiawan, I. G. N. A. (2014). Analisis Standarisasi Laboratorium Biologi Dalam Proses Pembelajaran di SMA Negeri Kota Denpasar. E-Journal Program Pascasarjana Universitas Pendidikan Ganesha, 4, 1-10.

Menteri Pendidikan Nasional Republik Indonesia. (2007). Peraturan Menteri Pendidikan Nasional Republik Indonesia No. 24 Tahun 2007 Tentang Standar Sarana dan Prasarana Untuk Sekolah Dasar/Madrasah Ibtidaiyah (SD/MI), Sekolah Menengah Pertama/Madrasah Tsanawiyah (SMP/MTs), dan Sekolah Menengah Atas/Madrasah Ali. In Menteri Pendidikan Nasional Republik Indonesia. Jakarta: Menteri Pendidikan Nasional Republik Indonesia.

Menteri Pendidikan Republik Indonesia. (2008). Peraturan Menteri Pendidikan Nasional Republik Indonesia Nomor 26 Tahun 2008 Tentang Standar Tenaga Laboratorium Sekolah/Madrasah. Jakarta.

Nikmah, S., Hartono, \& Sujarwata. (2017). Kesiapan dan Pemanfaatan Laboratorium Dalam Mendukung Pembelajaran Fisika 
SMA di Kabupaten Brebes. Unnes Physics Education Jurnal, 6(1), 1-8.

Pujani, N. M. (2014). Pengembangan Perangkat Praktikum Ilmu Pengetahuan Bumi dan Antariksa Berbasis Kemampuan Generik Sains untuk Meningkatkan Keterampilan Laboratorium Calon Guru Fisika. Jurnal Pendidikan Indonesia, 3 (2): 471-484

Putri, D. H., Risdianto, E. \& Sutarno. (2017). Identifikasi Keterlaksanaan Praktikum Fisika SMA dan PembekalanKeterampilan Abad 21. Prosiding Seminar Nasional Sains dan Enterpreneurship IV, 114-122

Sakti, I. (2011). Korelasi Pengetahuan Alat Praktikum Fisika dengan Kemampuan Psikomotorik Siswa di SMA Q Kota Bengkulu. Jurnal Exacta, IX(1), 67-76.

Sugiyono. (2009). Metode Penelitian Pendidikan (Pendekatan Kuantitatif, Kualitatif, dan R\&D). Bandung: Alfabeta.

Sunardiyo, S. (2014). Kinerja Tenaga Laboran dan Teknisi Laboratorium Rekayasa di Fakultas Teknik Universitas Negeri Semarang dan Faktor Faktor Dominan yang Mempempengaruhinya. Invotec, X(2), 121130.

Susilawati, Khoiri, N., Wijayanto, Masturi \& Xaphakdy, S. 2018. Learning Experience of Pre-service Physics Teachers in Developing Simple Project Loaded by Life Skills. Jurnal Pendidikan IPA Indonesia, 7 (1): 122-129

Susilawati. (2020). Eksplorasi Konten, Keterampilan Argumentasi, Diskusi Ilmiah dan Interaksi Keterampilannya dengan Pengetahuan Konseptual Induksi Magnetik. Jurnal Penelitian Pembelajaran Fisika, 11 (1): 69-74

Suwardi. (2016). Efektivitas Pelatihan Asisten Praktikum Dalam Meningkatkan Kompetensi Asisten di Laboratorium Fisika FMIPA Universitas Bengkulu. Integeated Lab Journal, 4(1), 1-10. 